\title{
The impact of personal and cultural beliefs on medication adherence of patients with chronic illnesses: a systematic review
}

This article was published in the following Dove Press journal:

Patient Preference and Adherence

\section{Wejdan Shahin \\ Gerard A Kennedy \\ leva Stupans}

School of Health \& Biomedical Sciences, RMIT University, Bundoora, Victoria

3083, Australia
Correspondence: Wejdan Shahin School of Health \& Biomedical Sciences, RMIT University, 289 Mckimmies Road, Bundoora, Victoria 3083, Australia Tel +6I 434961996

Email wejdan.shahin@rmit.edu.au
Background: Patients' adherence to therapeutic regimes may be influenced by subjective beliefs about chronic conditions. One of the challenges for health professionals in enhancing adherence is taking patients' understanding into account when giving health advice and/or providing medical treatment.

Purpose: This review aimed to evaluate the consequent effects of personal and cultural beliefs on medication adherence, in patients with chronic conditions such as hypertension, diabetes mellitus, chronic obstructive pulmonary disease and asthma.

Method: A systematic review methodology was used. PubMed, CINAHL, EMBASE and PsychINFO, databases were searched for relevant articles. The main terms analyzed were illness perceptions, health beliefs, cultural beliefs, chronic conditions and medication adherence.

Results: From 2,646 articles, 127 were retained for further assessment, and finally 25 met the inclusion criteria. A cross-sectional questionnaire survey research design was conducted in all included articles. Of these most $(n=22)$ targeted hypertension or diabetes mellitus. A number of personal and cultural based factors were identified as being associated with adherence to medication regimes - $40 \%$ of articles $(n=10)$ examined perception of illness, $20 \%(n=5)$ health literacy, $16 \%(n=4)$ cultural beliefs, $12 \%(n=3)$ self-efficacy, $16 \%(n=4)$ spiritual and religious beliefs, as well as $20 \%(n=5)$ illness knowledge. Statistically significant associations between medication adherence and these personal and cultural factors were found in $80 \%(n=20)$ of the included studies. However, the direction of associations varied between studies depending on the factor that was examined.

Conclusion: This review has evaluated the impact of personal and cultural factors on medication adherence and highlighted the gaps in literature regarding adherence. Further research is required to fully identify the associations between religious beliefs, control beliefs and illness knowledge and medication adherence.

Keywords: perception of illness, health beliefs, culture, medication adherence, diabetes mellitus, hypertension, asthma, chronic obstructive pulmonary disease

\section{Introduction}

Chronic illness is a significant worldwide health problem, with the numbers of people affected steadily increasing. World Health Organization (WHO) data show that uncontrolled hypertension rose from 600 million people to nearly one billion from 1980 to 2008 and in a similar period the number of people with diagnosed type 2 diabetes mellitus (DMT2) rose from 108 to 422 million. ${ }^{1,2}$

The treatment of chronic illnesses commonly includes the long-term use of pharmacotherapy. Although medications are effective in addressing chronic illnesses, their full 
benefits are often not realized due to lack of adherence. Levels of adequate adherence to diabetes (DMT2) and hypertension (HTN) treatment regimens vary widely with estimates from $36-93 \%$ for DMT2 and 30-70\% for HTN. ${ }^{3,4}$ Up to $50 \%$ of patients who are diagnosed with chronic obstructive pulmonary disease (COPD) fail to take medications as directed and many do not use inhalers effectively. ${ }^{5}$ Similarly, it is estimated that $30-70 \%$ of asthma suffers are not adherent to preventative medications. ${ }^{6}$ The consequences of non-adherence include; significant worsening of disease, treatment failure, increased hospitalizations and increased health care costs. ${ }^{7}$

Adherence is defined as the process by which patients take their medication as prescribed ${ }^{8}$ Patients' acceptance of medical advice, including medication use, may be influenced by subjective beliefs about their health condition. Therefore, it is essential to take beliefs into account when giving health advice and/or providing medical treatment. ${ }^{3}$ It has been shown that medication adherence is multi-faceted. Factors contributing to medication adherence include illness perceptions, health literacy, self-efficacy, cognitive abilities such as memory, coping and problem-solving skills, as well as psychosocial factors such as personal and cultural beliefs related to medication taking. ${ }^{9}$

Factors of concern to patients, regarding their illness, may be conceptualized as patients' illness perceptions. Leventhal and his colleagues proposed the common-sense model of illness representation to understand the processes by which people make sense of illness. ${ }^{10}$ Illness perceptions are personal beliefs and expectations about an illness or somatic symptoms. The basic assumption underlying this model is that illness perceptions, along with "common sense," are used in interpreting the meaning of illness or somatic symptoms, deciding on a response, and evaluating the effectiveness of the response. ${ }^{11}$

Personal beliefs about illness include both cognitive and emotional representations. Cognitive beliefs include five core domains: (1) "identity" describes peoples' beliefs about the label of illness and symptoms, and sets out the targets for change (such as to eliminate symptoms); (2) "timeline" refers to people's perception of the duration of illness, including symptoms and recovery; (3) "consequences" refers to beliefs about the seriousness of the disease and the impacts on daily life; (4) "control" refers to perceptions about the amenability of the illness to being cured, prevented or treated; and (5) "causes" refers to people's perceptions of the possible causes of their condition. Emotional representations are the feelings that arise as a result of illness, such as anxiety and/or depression. ${ }^{12}$

In explaining health behaviors, social determinants such as spirituality and religiosity have been increasingly identified as impacting health and treatment. ${ }^{7}$ Though often used interchangeably, spirituality and religiosity are separate, but related, concepts. While spirituality denotes an inner freedom to engage in faith and a relationship with a Supreme Being, such as God, religion refers to the outward adherence to highly prescribed beliefs, practices and rituals related to the Supreme Being, such as church attendance and associated activities. ${ }^{13}$ Cultural beliefs, defined as "a set of behavioral patterns related to thoughts, manners and actions, which members of society have shared and passed on to succeeding generations" 14 may also influence the decision making of patients with chronic disease to take medication. ${ }^{14}$ Acculturation has been defined as culture change that results from continuous contact between two distinct cultural groups; it also refers to changes in an individual whose cultural group is collectively experiencing acculturation. ${ }^{15}$

Health behaviors in the self-management of chronic diseases can also be affected by both health literacy and self-efficacy. ${ }^{16}$ High health literacy, ie, "the cognitive and social skills which determine the motivation and ability of individuals to gain access to, understand and use information in ways which promote and maintain good health"17 and high self-efficacy, ie, "the belief in one's capacity to organize and execute the courses of action required to manage a prospective situation " ${ }^{17}$ are more likely to have better adherence to self-care tasks and medication adherence. $^{18}$

In this review, we update and expand an earlier review ${ }^{9}$ to take into account findings from recent literature. Since 2006, a number of studies have been published which have examined illness perceptions conceptualized by the common sense model. Secondly, studies examining the impact of acculturation and religious beliefs on medication adherence have now also been published.

Although a number of systematic reviews on medication adherence have been conducted, ${ }^{12,19-21}$ none of these has explored the relationship between medication adherence and personal and cultural beliefs of patients with chronic diseases such as HTN, COPD, asthma and DMT2. These chronic diseases are currently the most significant in terms of population health in first-world countries.

\section{Methods}

\section{Search strategy}

The Preferred Reporting Items for Systematic Reviews and Meta-Analyses (PRISMA) guidelines ${ }^{22}$ were followed. The 
electronic databases (CINHAL, EMBASE, PsychINFO and PubMed) were systematically and extensively searched to identify the articles related to the effect of personal and cultural beliefs on medication adherence in chronically ill patients with HTN, DMT2, COPD and asthma. Outlined in Table 1 is the combination of search terms that were used to source the relevant literature. The search was conducted in August 2018, and rechecked in May 2019. This review is an update of a previously published systematic review; ${ }^{9}$ therefore, limitations were placed around the search strategy, March 2006-December 2018.

\section{Study selection}

Studies that met the inclusion criteria were selected initially, based on screening the titles and abstracts by one researcher (W.S.). Copies of the full-text papers deemed potentially relevant by the first screening were subsequently, independently fully analyzed by two researchers (W.S. and I.S.); in cases of disagreement about inclusion, the third author (G.K.) was consulted and consensus was reached.

\section{Inclusion criteria}

Articles were included if: (1) they pertained to one of the four main chronic illnesses: DMT2, HTN, COPD or asthma; (2) included a clear method of how medication adherence and beliefs were measured; and (3) addressed the association of beliefs and medication adherence.

\section{Exclusion criteria}

Articles were excluded if: (1) not peer-reviewed articles; (2) written in a language other than English; (3) focused on illnesses other than HTN, DMT2, COPD or asthma; (4) mentioned self-management behaviors, but not medication adherence; and (5) assessed the effect of medication beliefs on medication adherence.

\section{Data extraction process}

The data extracted from each eligible paper were synthesized and are presented in Tables 2-5. Table 2 shows a summary of major findings of the studies which examined the association of illness beliefs with medication adherence, Table 3 shows a summary of religious, cultural and personal and illness knowledge effects on medication adherence and Table 4 shows a summary of the impact of health literacy and self-efficacy on medication adherence.

Demographic characteristics and the tools used to measure beliefs and medication adherence are presented in Table 5 .

Table I Review search terms and databases reviewed

\begin{tabular}{|c|c|}
\hline Database & Search terms \\
\hline PubMed & $\begin{array}{l}\text { (Medication compliance OR medication taking behaviour OR medication adherence) AND (health beliefs OR religious beliefs } \\
\text { OR common sense model OR self-efficacy OR illness perception OR health literacy OR ("Health Knowledge, Attitudes, } \\
\text { Practice"[Mesh]) OR ("Culture"[Mesh])) AND (asthma OR diabetes mellitus OR chronic obstructive pulmonary disease OR } \\
\text { hypertension) } \\
\text { Limiters - published date: 0I/03/2006-0I/0I/2019; journal articles }\end{array}$ \\
\hline $\begin{array}{l}\text { CINAHL with full } \\
\text { text }\end{array}$ & $\begin{array}{l}\text { Chronic obstructive pulmonary disease OR diabetes mellitus OR asthma OR hypertension AND medication adherence OR } \\
\text { medication compliance OR medication persistence OR drug adherence OR drug compliance AND health beliefs OR illness } \\
\text { perception OR patient beliefs OR cultural beliefs OR common sense model OR acculturation OR health knowledge OR } \\
\text { health literacy OR self-efficacy OR religious beliefs } \\
\text { Limiters - published date: } 01 / 03 / 2006-01 / 01 / 2019\end{array}$ \\
\hline Embase & $\begin{array}{l}\text { ("chronic obstructive pulmonary disease" OR "diabetes mellitus" OR asthma OR hypertension) AND ("medication adher- } \\
\text { ence" OR "medication compliance" OR "medication persistence" OR "drug adherence" OR "drug compliance") AND } \\
\text { ("health beliefs" OR "illness perception" OR "patient beliefs" OR "cultural beliefs" OR "common sense model" OR } \\
\text { acculturation OR "health knowledge" OR "health literacy" OR "self-efficacy" OR "religious beliefs") } \\
\text { Limiters - published date: } 2006-2019\end{array}$ \\
\hline PsychINFO & $\begin{array}{l}\text { Chronic obstructive pulmonary disease OR diabetes mellitus OR asthma OR hypertension AND medication adherence OR } \\
\text { medication compliance OR medication persistence OR drug adherence OR drug compliance AND health beliefs OR illness } \\
\text { perception OR patient beliefs OR cultural beliefs OR common sense model OR acculturation OR health knowledge OR } \\
\text { health literacy OR self-efficacy OR religious beliefs } \\
\text { Limiters - Peer reviewed; published date: 01/03/2006-01/01/2019 }\end{array}$ \\
\hline
\end{tabular}


Table 2 Summary of associations between illness perceptions and medication adherence

\begin{tabular}{|c|c|}
\hline Study & Association between illness perceptions and medication adherence \\
\hline Chen et al, 2011 $1^{30}$ & $\begin{array}{l}\text { Significant association between illness perceptions variables and medication adherence: } \\
\text { Medication adherence associated positively with treatment control and personal control }(\beta=0.41, p<0.05) \text {. } \\
\text { Medication adherence associated negatively with illness identity }(\beta=0.23, p<0.05) \text {, and cause of illness }(\beta=-0.25 \text {, } \\
p<0.05) \text {. }\end{array}$ \\
\hline Ashur et al, $2015^{31}$ & $\begin{array}{l}\text { Significant association between Illness perceptions variables and medication adherence: } \\
\text { Medication adherence associated positively with treatment control }(p=0.04, \mathrm{OR}=0.95,95 \% \mathrm{Cl}=0.9 \mathrm{I}-0.99) \text {. } \\
\text { Medication adherence associated negatively with illness identity }(p=0.008, \mathrm{OR}=1.08,95 \% \mathrm{Cl}=1.02-1.14) \text {. }\end{array}$ \\
\hline Chen et al, $2009^{29}$ & $\begin{array}{l}\text { Significant associations between illness perceptions variables and medication adherence: } \\
\text { Medication adherence associated positively with personal control }(\beta=0.14, p<0.05) \text { and treatment control }(\beta=0.20 \text {, } \\
p<0.00 \mathrm{I}) \text {. } \\
\text { No significant association between illness identity and medication adherence }(\beta=-0.09, p>0.05) \text {. } \\
\text { No significant association between emotional representation of illness and medication adherence }(\beta=-0.09, p>0.05) \text {. } \\
\text { Medication adherence associated negatively with psychological cause of illness }(\beta=-0.23, p<0.00 \mathrm{I}) \text { and illness con- } \\
\text { sequences }(\beta=-0.12, p<0.05) \text {. }\end{array}$ \\
\hline Mann et al, $2009^{4}$ & $\begin{array}{l}\text { Significant associations were found between illness perceptions variables and medication adherence: } \\
\text { Medication adherence associated positively with personal control }(p=0.003) \text {. } \\
\text { Medication adherence associated negatively with beliefs about illness consequences }(p=0.03) \text { and identity }(p=0.002) \text {. }\end{array}$ \\
\hline Jacobs et al, $2014^{11}$ & $\begin{array}{l}\text { Significant moderate associations were found between illness perceptions variables and medication adherence: } \\
\text { Medication adherence associated negatively with beliefs about illness consequences }(r=0.383, p<0.05) \text {. } \\
\text { Medication adherence associated negatively with illness emotional representation }(r=0.528, p<0.00 \mathrm{I}) \text {. }\end{array}$ \\
\hline Hsiao et al, $2012^{3}$ & $\begin{array}{l}\text { Significant associations between illness perceptions variables and the adherence: } \\
\text { Medication adherence associated positively with positive beliefs with regard to timeline, consequences and emotional } \\
\text { responses }(p<0.05) \\
\text { Medication adherence associated negatively with personal control }(p<0.05) \text {. }\end{array}$ \\
\hline Saarti et al, $2016^{32}$ & No significant association between illness perceptions and medication adherence $(p=0.52, \mathrm{OR}=1.0, \mathrm{Cl}=0.9-1.0)$. \\
\hline Krauskopf et al, $2015^{5}$ & $\begin{array}{l}\text { No significant association between illness identity }(p=0.46) \text {, consequences }(p=0.15) \text {, personal control }(p=0.76) \text {, timeline } \\
\text { of illness }(p=0.79) \text { with medication adherence. } \\
\text { Negative association between emotional representation of illness and medication adherence }(p=0.00 \mathrm{I})\end{array}$ \\
\hline Rajpura \& Nayak, $2014^{25}$ & Positive association between threatening perceived illness burden and medication adherence $(r=0.332, p<0.00 \mathrm{I})$. \\
\hline Aflakseir, $2012^{34}$ & $\begin{array}{l}\text { Significant association between illness perceptions variables and the adherence: } \\
\text { Medication adherence associated positively with illness timeline }(p<0.05) \text {. } \\
\text { Medication adherence associated negatively with illness consequences }(p<0.05) \text {. }\end{array}$ \\
\hline
\end{tabular}

\section{Risk of bias in individual studies}

To ascertain the validity of eligible cross-sectional studies, each study was assessed for the following eight components based on the checklist for quasi-experimental studies (non-randomized experimental studies): ${ }^{23}$ (1) clearly defining the criteria for inclusion in the sample; (2) detailed description of the study subjects and the setting; (3) validity and reliability of ways measuring the exposure; (4) criteria used for measurement of the condition; (5) identifying confounding factors; (6) strategies to deal with confounding factors; (7) validity and reliability of the outcomes measures and (8) appropriate statistical analyses used.

\section{Results}

\section{Article selection}

The literature search located 2,642 articles; hand searching retrieved four additional references. Subsequently, 937 duplicates were removed, and the titles and abstracts of the remaining 1,673 articles were reviewed. 127 articles were directly related to the aims of this review. A further detailed review of the full-text articles resulted in elimination of additional 102 


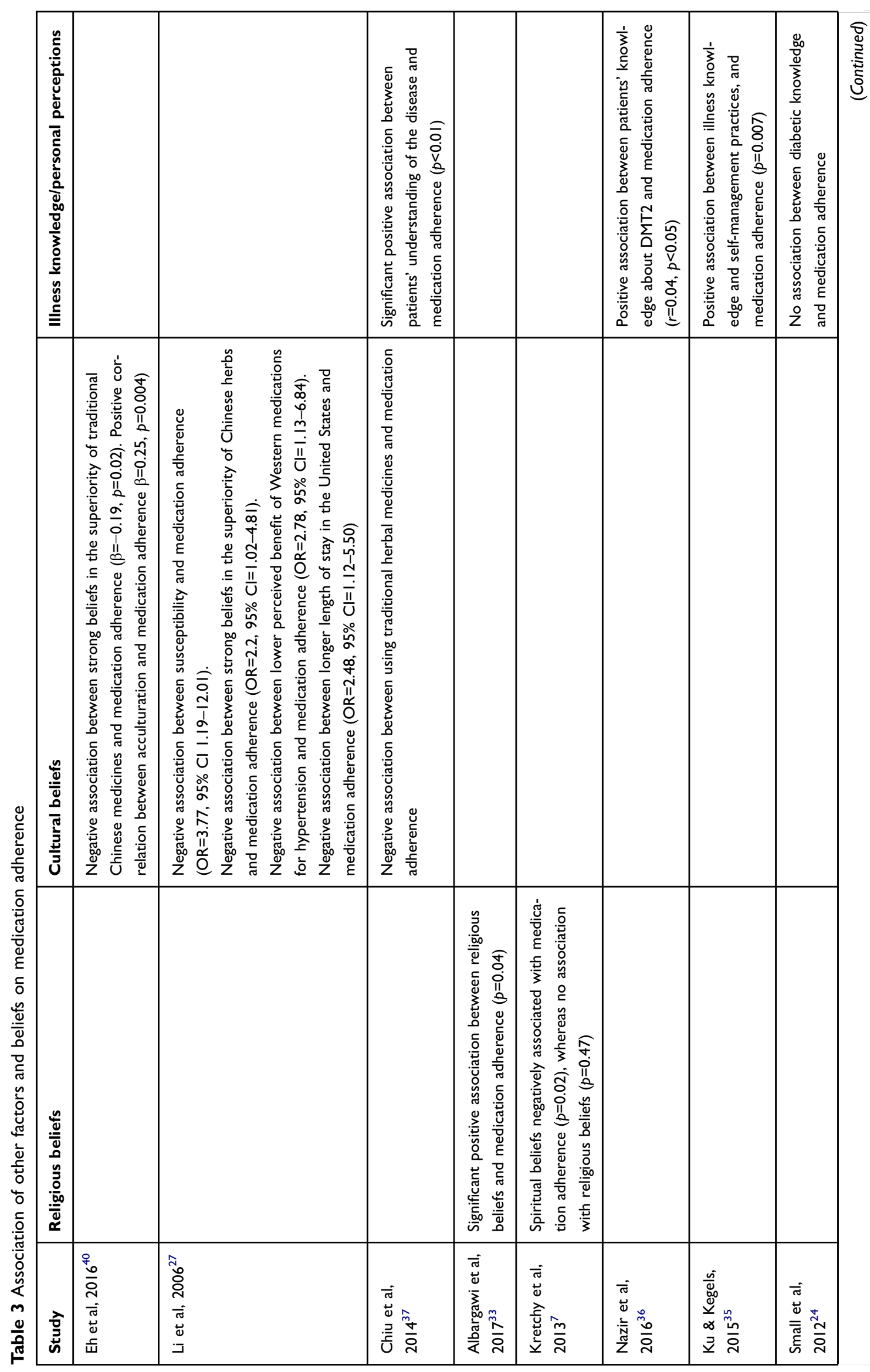




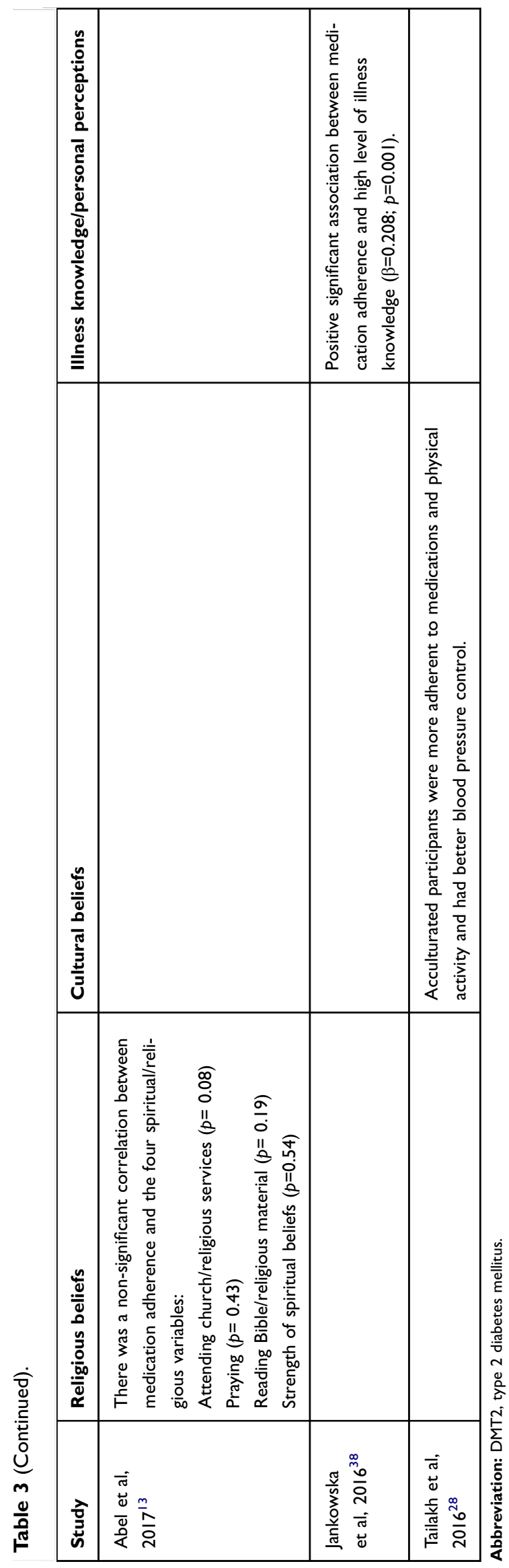

articles. We selected a final set of 25 articles that met the inclusion criteria. For article screening and the exclusion process, please see the PRISMA Flow Chart (Figure 1).

\section{Characteristics of selected studies}

All studies selected were cross-sectional and included surveys. Most of the studies were focused on patients diagnosed with DMT2 $(44 \%, 11 / 25)$ or HTN $(44 \%, 11 /$ 25). An additional two studies were conducted in patients with asthma, and only one study focused on COPD. Illness perception was the most frequently investigated belief reported in $42 \%(8 / 19)$ of the studies.

Eleven of the studies were conducted in the United States of America, ${ }^{4,5,11,13,16,18,24-28}$ three in Taiwan, ${ }^{3,29,30}$ four in Middle-Eastern countries (Lebanon, Libya, Saudi Arabia and Iran),${ }^{31-34}$ one in the Philippines, ${ }^{35}$ one in Pakistan, ${ }^{36}$ one in Ghana, ${ }^{7}$ one in unspecified Asian countries, ${ }^{37}$ one in Poland, ${ }^{38}$ one in Thailand ${ }^{39}$ and one in Australia. ${ }^{40}$ A number of personal- and cultural-based factors were identified as being associated with adherence to medication regimes. These included; perception of illness, health beliefs and literacy, cultural beliefs, spiritual and religious beliefs, as well as illness knowledge.

\section{Risk of bias across studies}

All the studies provided clear, detailed and specific inclusion criteria to recruit study participants and provided a specific diagnosis for the participants. Both the exposure and the outcome were measured in valid and reliable ways; reliable and valid questionnaires (Cronbach's alpha $=0.6-0.79$ ) have been used in all the included studies. Confounding factors were identified and addressed in 24 studies. Although convenience samples were used in all the studies, representativeness of the sample was described as one of the limitations in most of the included articles, and most also reported that generalization of results might be limited.

\section{Findings of individual studies Perception of illness}

Nine studies investigated the role of beliefs related to emotional and cognitive domains of chronic illnesses on medication adherence..$^{3-5,11,29-32,34}$ These beliefs were found to be associated with medication adherence in seven studies..$^{3-5,11,29-31}$ One study reported that medication adherence was affected only by the patients' evaluation of the process of taking medication, its short-term 
Table 4 Association of health literacy and self-efficacy on medication adherence

\begin{tabular}{|c|c|c|}
\hline Study & Health literacy & Self-efficacy \\
\hline Ku \& Kegels, $2015^{35}$ & & $\begin{array}{l}\text { Positive association identified between perceived self- } \\
\text { efficacy and all four self-management practices (diet } \\
p<0.00 \mathrm{I} \text {, medication adherence } p=0.004 \text {, health care } \\
\text { provider consultation } p<0.00 \mathrm{I} \text { and exercise } p<0.00 \mathrm{I} \text { ) }\end{array}$ \\
\hline Shiyanbola et al, $2017^{26}$ & $\begin{array}{l}\text { No direct relationship with medication adherence; how- } \\
\text { ever, mediated other factors related to medication } \\
\text { adherence, such as illness perception }(\beta=0.20, p=0.002) \\
\text { and medication beliefs }(\beta=-0.156, p=0.014)\end{array}$ & $\begin{array}{l}\text { Significant positive association between self-efficacy and } \\
\text { adherence }(\beta=0.486, p<0.00 \mathrm{I})\end{array}$ \\
\hline Soones et al, $2017^{18}$ & $\begin{array}{l}\text { Directly associated positively with medication adherence } \\
(\beta=0.089, p<0.00 \mathrm{I}) \text { and indirectly mediated by medica- } \\
\text { tion concerns }(\beta=0.03, p=0.002) \text {. }\end{array}$ & \\
\hline Huang et al, $2018^{16}$ & $\begin{array}{l}\text { No significant association with diabetes medication } \\
\text { adherence }(\beta=-0.04, p=0.59) \text {. }\end{array}$ & $\begin{array}{l}\text { Significant positive association between self-efficacy and } \\
\text { adherence }(\beta=0.53, p<0.00 \mathrm{I})\end{array}$ \\
\hline Wannasirikul et al, $2016^{39}$ & $\begin{array}{l}\text { Directly associated positively with medication adherence } \\
(\beta=0.08, p<0.05) \text {, and indirectly mediated by literacy }(\beta \\
=0.17, p<0.05) \text { and cognitive ability }(\beta=0.02, p<0.05)\end{array}$ & \\
\hline
\end{tabular}

effects and the longer term outcomes associated with taking it (Table 2). ${ }^{32}$

Five studies described beliefs that related medication adherence to control beliefs (personal and/or treatment control). ${ }^{3,4,29-31}$ These beliefs were significantly and positively associated with medication adherence in four studies, ${ }^{4,29-31}$ and negatively associated in only one study, which found that patients who felt unable to control their blood pressure were more adherent to medications (Table 2). ${ }^{3}$

Five studies explored beliefs about illness identity. ${ }^{4,5,29-31}$ A negative association with medication adherence was found in three studies, which suggested that patients who experience more symptoms may perceive less ability to control their illness (Table 2). ${ }^{4,30,31}$ Two studies found no significant association between illness identity and medication adherence (Table 2). ${ }^{5,29}$

Five studies examined the association of beliefs related to illness consequences with medication adherence. ${ }^{3,4,11,29,34}$ A negative association was found in four studies $4,11,29,34$ whereas one study found a positive correlation. ${ }^{3}$ Three studies mentioned beliefs about the timeline of illness. ${ }^{3,29,34}$ Two studies demonstrated negative association with medication adherence, ${ }^{3,29}$ whereas one study found that patients who believe that diabetes is a chronic illness have higher level of adherence ${ }^{34}$ (Table 2).

Two studies found an association of perceived causes of illnesses and adherence. ${ }^{29,30}$ More casual attributions to psychological factors and less attribution to causality of risk factors were negatively associated with medication adherence (Table 2). ${ }^{29,30}$ Cause was associated positively with illness identity; individuals who reported more symptoms tend to seek more causal attributions, perceived the illness to be more negative and less controllable, and therefore were less likely to adhere to medication. ${ }^{30}$

Four studies explored the effect of emotional representations of illness on medication adherence, ${ }^{3,5,11,29}$ and three of them found that negative emotional representations correlated negatively with medication adherence ${ }^{3,5,11}$ (Table 2), whereas no significant association was found in the fourth study (Table 2). ${ }^{29}$

One study provided insights into how illness perceptions and burden relate to medication adherence. Findings suggested positive significant association between medication adherence and the threatening view of illness, whereas there was a negative association with a greater perceived burden of illness (Table 2). ${ }^{25}$

\section{Cultural beliefs}

Four studies investigated the influence of cultural beliefs on adherence and self-management (Table 3). 27,28,37,40

Participants in one study who had stronger beliefs in the effectiveness of Traditional Chinese Medication and traditional Chinese health beliefs were found to be less likely to be acculturated and less adherence to self-management and medication. ${ }^{40}$ Another study focusing on Arab Americans 


\begin{tabular}{|c|c|c|c|c|c|c|c|c|c|c|c|c|}
\hline \multicolumn{3}{|c|}{ 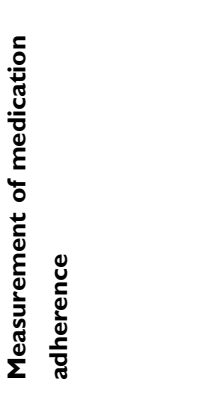 } & 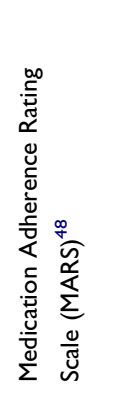 & 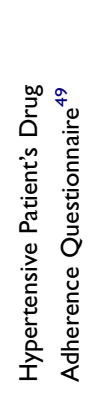 & 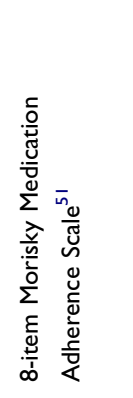 & 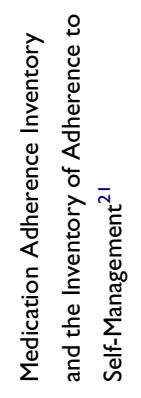 & 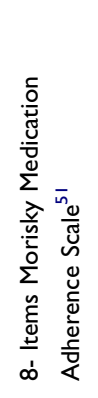 & 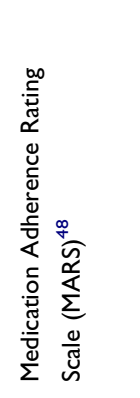 & 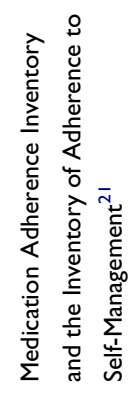 & 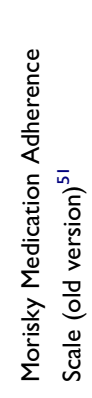 & 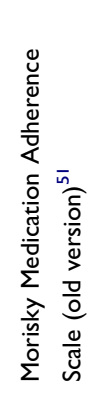 & 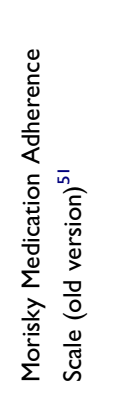 \\
\hline \multicolumn{3}{|l|}{ 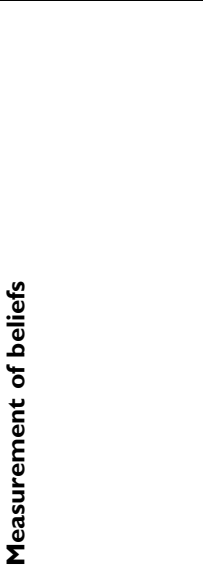 } & 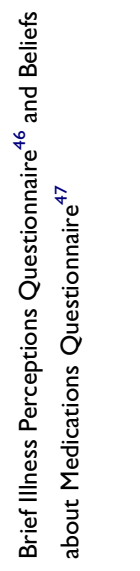 & 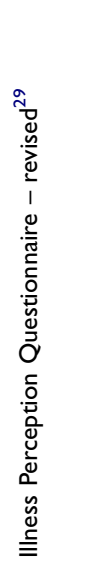 & 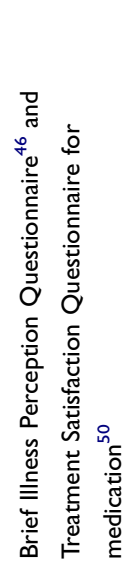 & 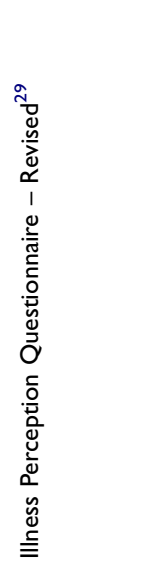 & 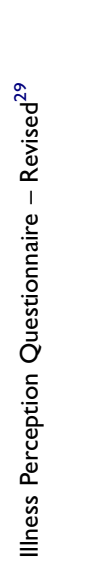 & 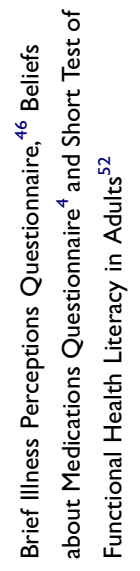 & 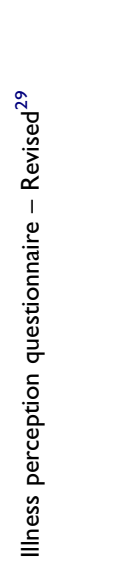 & 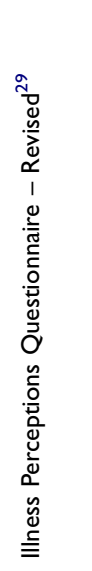 & 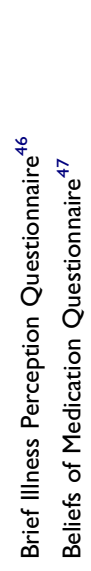 & 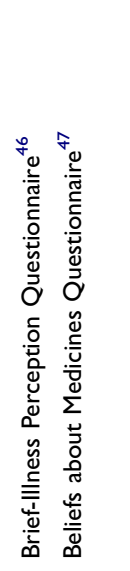 \\
\hline \multicolumn{3}{|c|}{ 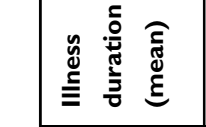 } & $\stackrel{\mathbb{z}}{\mathbf{z}}$ & $\overleftarrow{\Sigma}$ & $\stackrel{\infty}{\sim}$ & $\begin{array}{l}\text { fo } \\
\text { Oे }\end{array}$ & $\stackrel{\Delta}{\sigma}$ & $\frac{\dot{T}}{m}$ & $\begin{array}{l}\stackrel{0}{0} \\
\stackrel{0}{0}\end{array}$ & $\stackrel{\partial}{\sigma}$ & 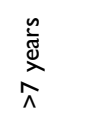 & $\stackrel{\circ}{\underline{m}}$ \\
\hline \multirow{4}{*}{ 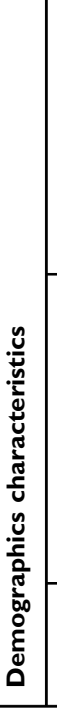 } & \multicolumn{2}{|c|}{ 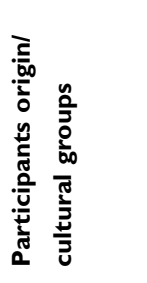 } & 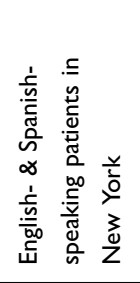 & 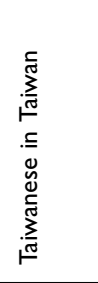 & 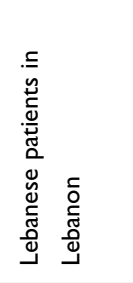 & 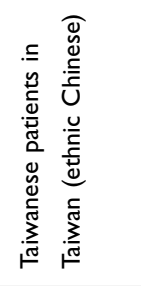 & 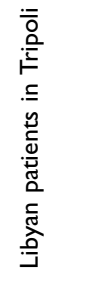 & 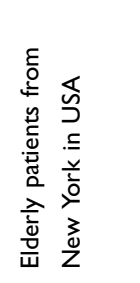 & 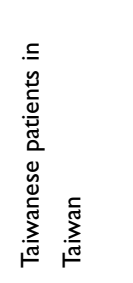 & 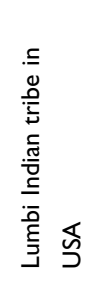 & 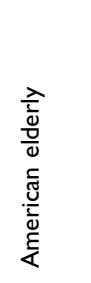 & 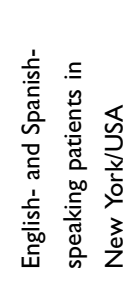 \\
\hline & & 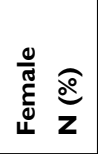 & $\begin{array}{l}\text { Ê } \\
\stackrel{0}{\simeq}\end{array}$ & $\begin{array}{l}\widehat{m} \\
\stackrel{p}{m} \\
0 \\
o \\
m\end{array}$ & 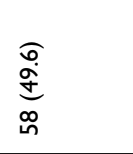 & $\begin{array}{l}\text { E. } \\
\text { o. } \\
\text { 主 }\end{array}$ & $\begin{array}{l}\sigma \\
\infty \\
0 \\
0 \\
\frac{\infty}{m}\end{array}$ & 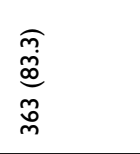 & $\begin{array}{l}\frac{\widehat{o}}{\bar{d}} \\
\equiv \\
\equiv\end{array}$ & $\begin{array}{l}\widehat{\text { ch }} \\
\text { م }\end{array}$ & $\begin{array}{l}\sigma \\
\hat{\sigma} \\
\tilde{c} \\
\tilde{f}\end{array}$ & 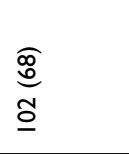 \\
\hline & & 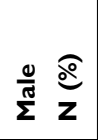 & $\begin{array}{l}\widehat{\tilde{m}} \\
\text { }\end{array}$ & 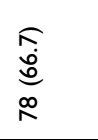 & $\begin{array}{l}\widehat{F} \\
\text { 号 } \\
\text { ôn } \\
\text { in }\end{array}$ & 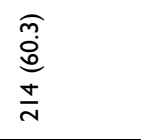 & $\begin{array}{l}\widehat{\bar{\Xi}} \\
\frac{\underline{ \pm}}{N}\end{array}$ & 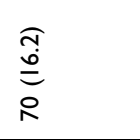 & 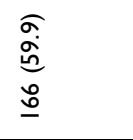 & 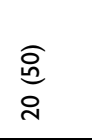 & 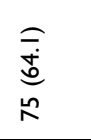 & $\begin{array}{l}\text { ल্ } \\
\text { og }\end{array}$ \\
\hline & \multicolumn{2}{|c|}{ 怘 } & 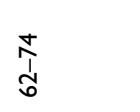 & $\stackrel{\infty}{n ٍ n}$ & $\frac{\infty}{\Lambda}$ & นี่ & 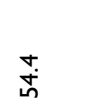 & $\hat{o}$ & $\frac{\infty}{\Lambda}$ & 亡ீ. & 㞻 & in \\
\hline \multicolumn{3}{|c|}{ 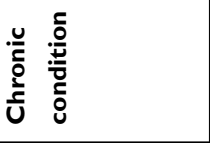 } & $\begin{array}{l}0 \\
\text { Oे } \\
\text { on }\end{array}$ & $\underset{\text { 罙 }}{\text { z }}$ & 叒 & 罙 & $\stackrel{E}{E}$ & 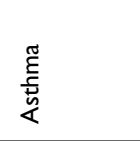 & 罙 & $\sum_{D}^{E}$ & $\underset{\text { 罙 }}{\text { z }}$ & $\sum_{0}^{E}$ \\
\hline \multicolumn{3}{|l|}{ 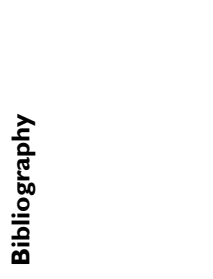 } & 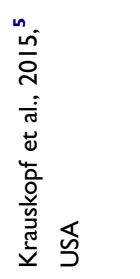 & 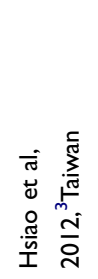 & 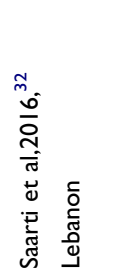 & 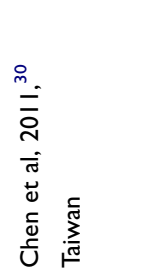 & 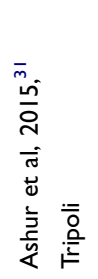 & 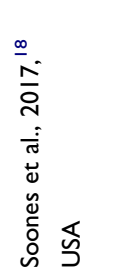 & 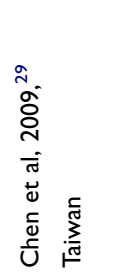 & 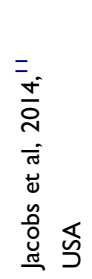 & 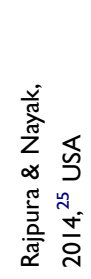 & 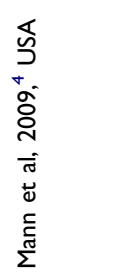 \\
\hline
\end{tabular}




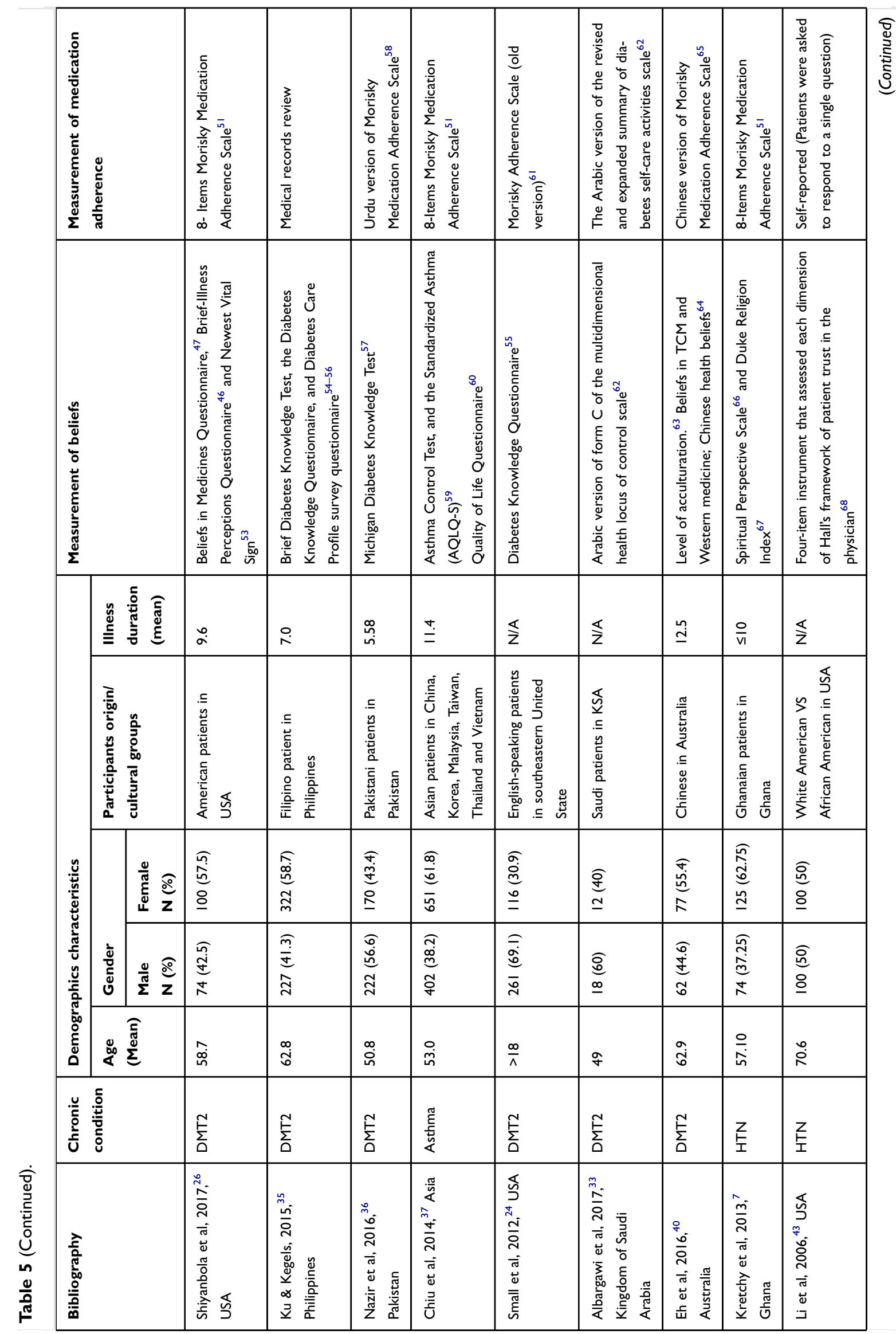




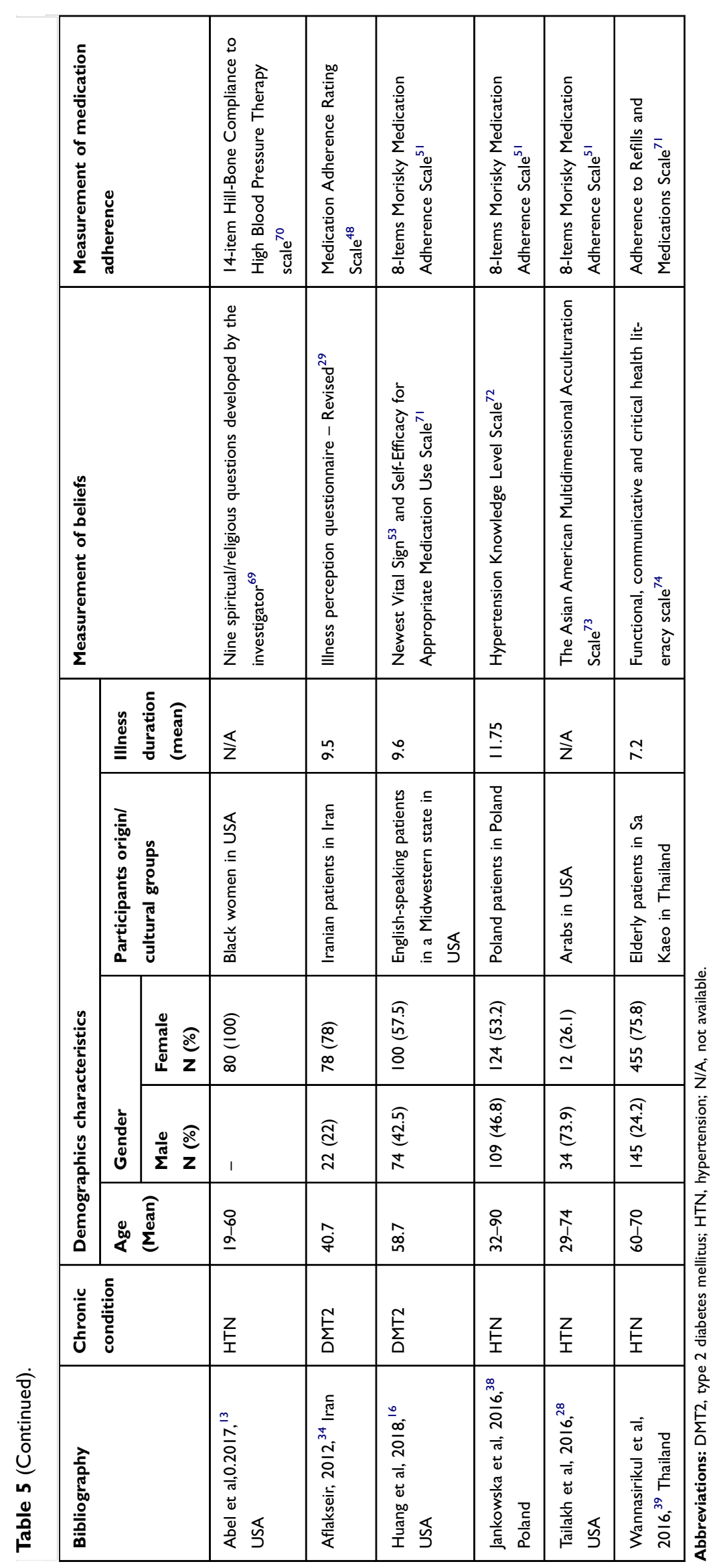




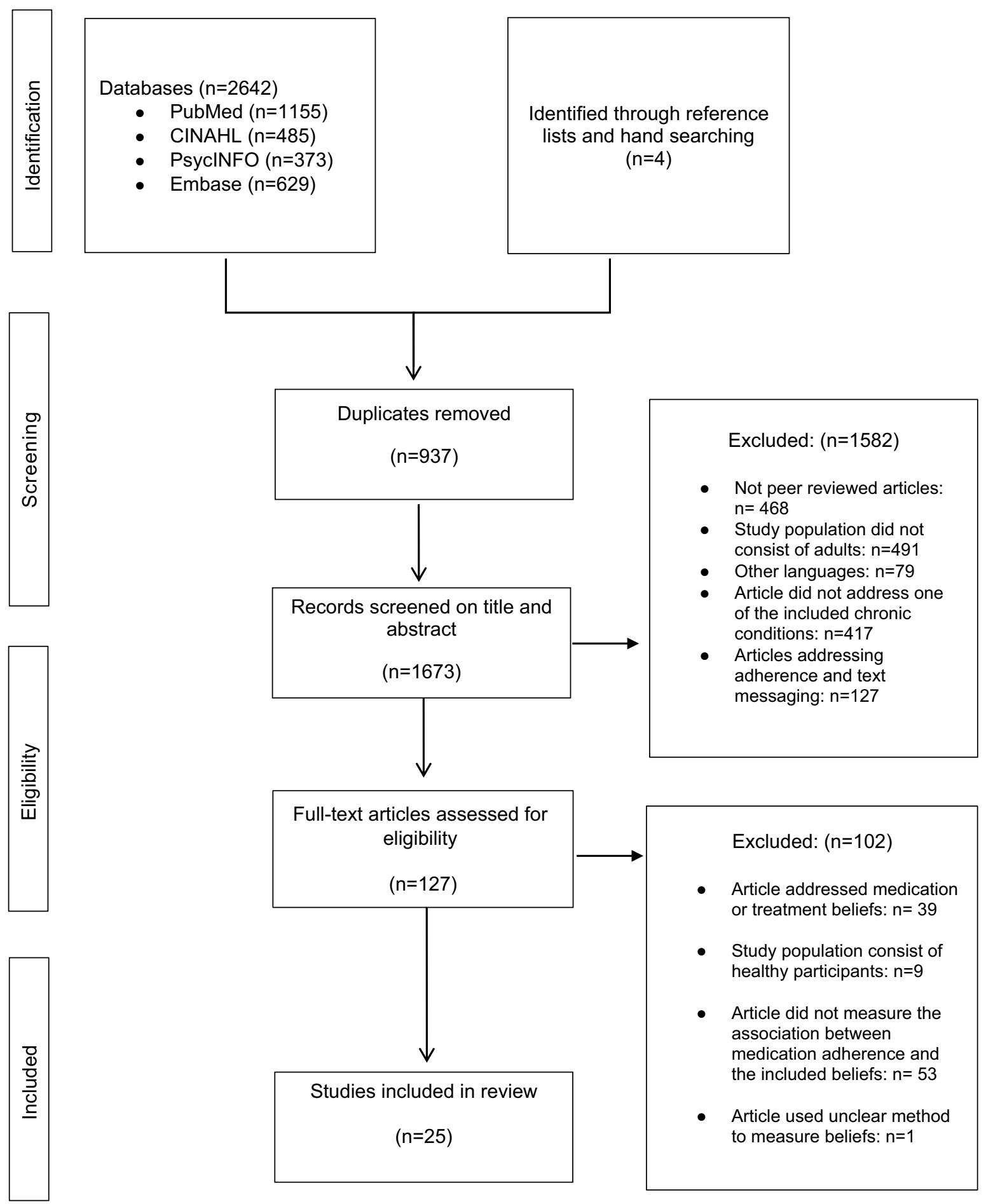

Figure I PRISMA flow chart of the literature search and study selection.

in the USA found that those with high level of acculturation were most likely to be adherent to antihypertensive medications. ${ }^{28}$ Four cultural factors, lower perceived susceptibility in general, higher perceived benefits of Chinese herbs, lower perceived benefits of Western medications and a longer duration of residence in the Western country investigated in another study, were associated with medication non-adherence in the case of hypertension. Chinese immigrants who believed that hypertension had an influence on their personal lives (perceived susceptibility in general) were more compliant with anti-hypertensive medications (Table 3). ${ }^{27}$ Another study investigated Asian patients' 
asthmatic perceptions, behaviors and the association with medication adherence in China, Korea, Malaysia, Taiwan, Thailand and Vietnam. Patients with low adherence were more likely to believe that using traditional herbal medicines is safer than inhalers. ${ }^{37}$

\section{Religious/spiritual beliefs}

Four studies examined religious beliefs, ${ }^{7,13,31,33}$ and two mentioned the contribution of spiritual beliefs to medication adherence and self-management (Table 3). ${ }^{7,13}$

Two studies conducted in the Middle-East examined the role of the Islamic religion. ${ }^{31,33}$ A study carried out in Saudi Arabia found that people who reported that they can follow their medication regimen, and perceived that God controls their health and illness, were found to have good adherence to taking their medication ${ }^{33}$ (Table 3 ). The most common perceived cause of DMT2 in a Libyan study was found to be Allah's will $(86.6 \%) .{ }^{31}$ In a study from Ghana, hypertensive patients, $90 \%$ of whom were Christians, exhibited high levels of both spirituality and religiosity. However, spirituality, not religiosity, was associated significantly with medication nonadherence (Table 3). The authors suggested that some patients would risk not taking their medications while anticipating divine healing outcomes. ${ }^{7}$ Another study carried out in the USA, focusing on Christian black women, found that attending church, praying and reading Bible/religious material, and having strong spiritual beliefs were not significantly associated with medication adherence ${ }^{13}$ (Table 3 ).

\section{Knowledge and personal perceptions about illness}

Five studies examined the concept of illness knowledge and personal perceptions of chronic illnesses (Table 3). ${ }^{24,35-38}$ In a study that illuminated patients' perceptions of asthma management as well as the current status of asthma control and adherence in the participating Asian countries, adherence was significantly associated with patients' self-reported understanding of asthma, inhaler techniques and with patients' acceptance of inhaler medicines in terms of benefits, safety, convenience and cost. Better adherence was associated with better understanding of the disease. ${ }^{37}$ In line with these findings, two of the studies that focused on DMT2, ${ }^{35,36}$ and one focused on $\mathrm{HTN}^{38}$ reported that having the essential knowledge about the condition and the care for the condition was associated with a higher level of confidence of people with illness in their ability to perform selfcare and medication adherence (Table 3).

In contrast to previous findings related to knowledge and adherence, a study which examined the relationship between emotional coping and DMT2 knowledge, medication adherence and self-care behaviors in adults with DMT2 identified no significant associations with medication adherence and DMT2 knowledge. However, being active in communicating the emotional experience was positively related to self-care behaviors, and negatively with medication adherence. ${ }^{24}$

\section{Self-efficacy}

Perceived self-efficacy was the lone significant factor identified to be common among four self-care management behaviors (diet, medication adherence, health care provider consultation and exercise) in a study that measured factors potentially associated with self-management practices of people with DMT2. ${ }^{35}$ The significant association between self-efficacy and adherence was also mentioned in two other studies that examined health literacy in patients with DMT2. Self-efficacy was found to be correlated positively with medication adherence (Table 4). ${ }^{16,26}$

\section{Health literacy}

Four studies illustrated the impact of health literacy on medication adherence (Table 4). ${ }^{16,18,26,39}$ In two studies, health literacy was found to have no direct association with medication adherence, ${ }^{16,26}$ but it had a significant moderator effect on the relationship between adherence and medication concerns and illness perceptions in one study. ${ }^{26}$ However, in two studies, health literacy was found to have a direct effect as well as indirect effect on adherence, mediated by medication concerns in one study, ${ }^{18}$ and cognitive ability or literacy in the second one ${ }^{39}$ (Table 4). Across all health literacy levels, there was a significant negative association between threatening illness perceptions and medication adherence. For individuals with low and moderate health literacy, increased levels of threatening illness perceptions resulted in a sharp decline in medication adherence. ${ }^{18,26}$

\section{Discussion}

The findings of the majority of research papers included in this systematic review have demonstrated a significant relationship between illness perceptions and other beliefs and medication adherence, in patients with the selected chronic conditions. However, the direction of associations was not consistent amongst studies. Figure 2 presents a conceptual framework which has been adapted from two studies, ${ }^{26,30}$ and modified by the authors, to identify the associations of negative illness representation, the cause of illness, religiosity and cultural beliefs, and beliefs with regard to the control, self-efficacy and knowledge of medication adherence as 
identified in this review. We have also included the mediating effects of health literacy. Although this framework is not presenting the relationships of mediating effects between these beliefs, in fact these may exist.

Control of illness was the most significant predictor of a favorable outcome ${ }^{30}$ patients who believed in their own ability to control illness, and had strong confidence in treatment reported better medication adherence in many studies. ${ }^{4,25,29-31}$ Although one study reported a negative association between patients' beliefs about their control of illnesses and medication adherence, ${ }^{3}$ this discrepancy may be attributed to the fact that patients of this study had high numbers of symptoms and negative emotional responses towards their illness. Different characteristics of the samples, such as household incomes, educational levels or locus of control may have contributed as well; however, these were not reported.

Perception of a lower ability to control a health threat may imply an ineffectiveness of one's behavioral actions, or cognitive and emotional changes in illness representations because of somatic experiences. Higher control is associated with lower anxiety, lower avoidance/denial of coping strategies and positive reappraisal. ${ }^{30}$

Illness perceptions are influenced by somatic and symptomatic information that patients receive from health care professionals and the satisfaction with the information received. Once patients report symptoms after a diagnosis, inconsistency between symptom attributions of patients and health professionals may arise. Eventually, patients may adopt the perspective of professionals, but they will continue to try to understand their symptom experience based on personal perceptions, not the illness entity, and create more barriers to adherence to therapeutic regimens. ${ }^{29}$ Therefore, it is important prior to and during treatment to assess patients' views about their illness, symptoms, treatments and also their satisfaction with information received. ${ }^{41}$

Although two studies found no association between medication adherence and illness symptoms, ${ }^{5,29}$ a number of points may explain this inconsistency; the high educational level of the participants, and the fairly stable disease progression among patients who have long history of illness (diagnosed for more than 10 years). Evidence from the literature demonstrates that newly diagnosed patients with illness were more likely to drop out of treatment if they perceived the disease to be acute or experienced symptoms upon their first clinical visit. ${ }^{30}$ Additionally, adherence to medication is related to the particular condition. An asymptomatic nature of a disease, as well as clinical improvement, reduces patient motivation to take medications as prescribed. $^{8}$

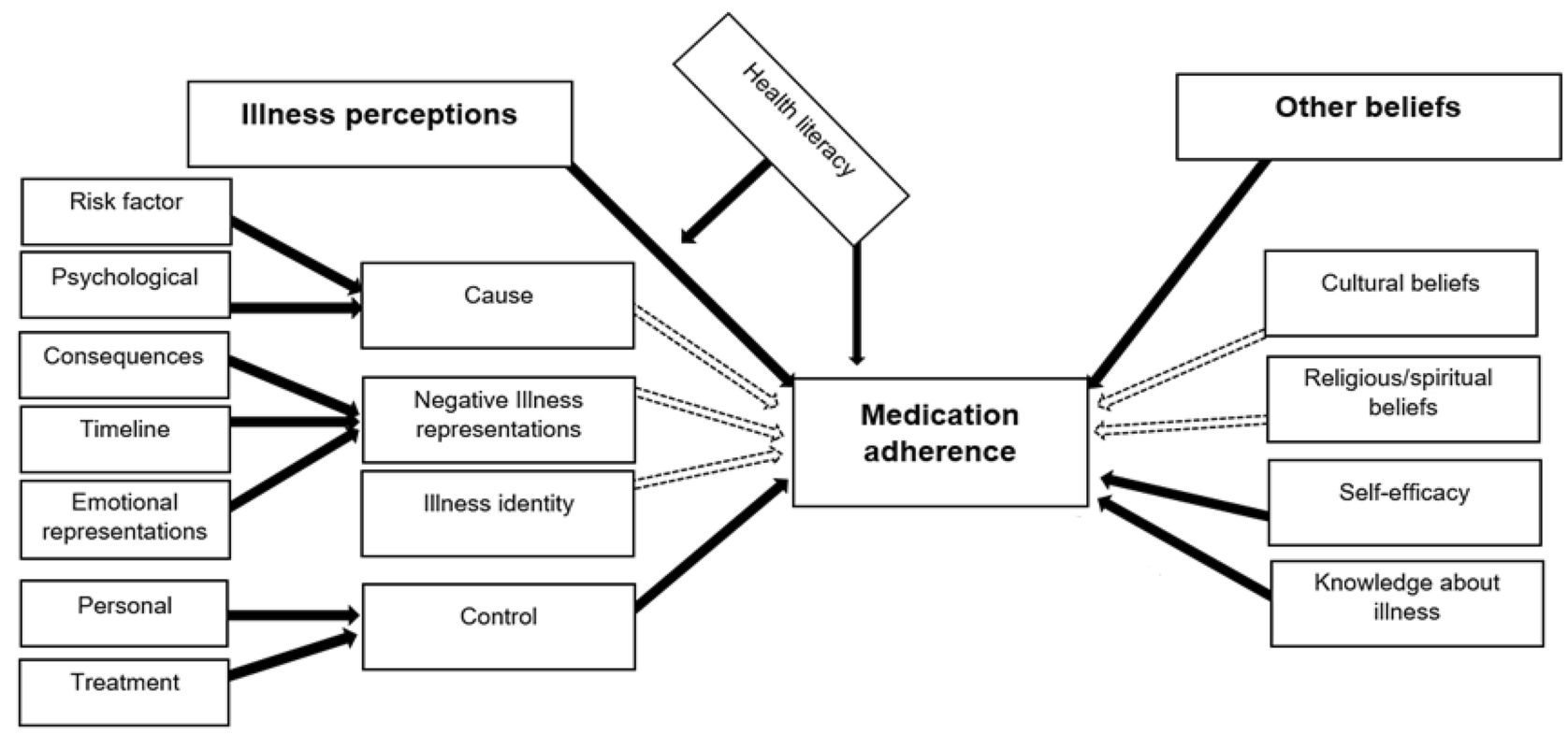

\begin{tabular}{|l|l|}
\hline Negative association or no association c=:=- $\Rightarrow$ & Positive association $\longrightarrow$ \\
\hline
\end{tabular}

Figure 2 Conceptual model to illustrate the effect of illness perceptions and other beliefs on medication adherences. Note: Data from these studies. ${ }^{26,30}$ 
Other beliefs such as spiritual, religious and cultural beliefs were demonstrated in this systematic review to have a significant effect on medication adherence. Spirituality and religiosity are increasingly identified as impacting health and treatment. ${ }^{7}$ Cultural influences may have direct impact on patient's adherence via perceptions of health and disease management. The health beliefs and cultural values of the culturally and linguistically diverse populations may differ from Western medical beliefs. ${ }^{40}$

Individuals vary within a group in their acculturation strategies (both their attitudes and actual behaviors) leading to variable behavioral repertoires. Thus, from this perspective, there is no expectation of one single acculturation pattern, but of highly variable strategies and outcomes that lead to variably successful long-term adaptations. $^{42}$

Factors that contributed to medication adherence can be classified as modifiable and non-modifiable factors. Age, gender and ethnicity are some of the nonmodifiable factors that can affect medication adherence. Personal and cultural beliefs discussed above are difficult to modify in patients who have chronic illnesses; however, these patients are amendable to counseling by health care providers; hence, patients' perceptions of their illness should be a target for intervention to enhance adherence to medications.

Patient trust in physicians is another modifiable factor, and an important facilitator of self-efficacy, and plays an important role in a patient's ability to maintain medication adherence. ${ }^{43}$ Physician communication training focused on positive and empathic communication can improve patient satisfaction, adherence and trust. ${ }^{44}$

Several clinical implications can be drawn from this systematic review. Understanding patients' pre-existing perceptions of illness before giving new information is required. In this way, health care professionals and patients have the opportunity to recognize gaps, confusions and misconceptions in the patient's perceptions. ${ }^{41}$ In addition, patients need to be educated about their illness, symptoms and medications. Health care providers play a major role in that regard, and a collaborative care approach can facilitate the education of patients about the benefits of medications and the importance of their continuous use. ${ }^{36}$ Health care providers should take into account the impact of religious and cultural background on health beliefs to provide sensitive care to diverse ethnic populations to achieve better medication adherence.
We also suggest that patients with negative illness perceptions and low health literacy may benefit from practical interventions, such as psycho-educational and cognitive-behavioral interventions. Interventions focusing on illness perceptions should first consider the individuals' numeracy skills by assessing in clinical settings, how well patients understand the implications of their blood sugar measurements, blood pressure results and practicalities of medication dosing, etc. Understanding the patients' numeracy skills will then allow for a more tailored approach to using simple and plain language to communicate their treatment during counseling. ${ }^{26}$

To improve comprehension and subsequent adherence, techniques should be tailored to the patient and context and may include using familiar language and pictures, contextualizing facts and behaviors, or providing audio or print materials. ${ }^{18}$

Poorer medication adherence in less acculturated patients might relate to their traditional health beliefs as well as ineffective communication with health care providers due to language barriers. ${ }^{40}$ We suggest that migrant patients need to learn the language of countries in which they resettle. In addition, migrants may often be best able to integrate themselves into the receiving society when they receive help, encouragement and tangible support resources from members of the local community. ${ }^{45}$

Non-adherence should not be perceived as only the patients' responsibility. On the contrary, social factors (such as social support, economic factors, etc.), health care-related factors (eg, barriers to health care and quality of provider-patient communication), condition characteristics, as well as therapy-related factors (such as patient friendliness of the therapy) play an important role in addressing adherence. ${ }^{8}$

\section{Limitations}

There were some limitations in the current review; some of the selected studies in this review used self-reports method to measure adherence, different tools were used to measure beliefs and also most of studies participants were recruited from a small geographic region, so findings of these studies may not be generalizable. A particular strength of the present review was our inclusiveness. We extended the previous review by examining illness perception according to the common-sense model, included the impact of knowledge, religiosity and spirituality, in a number of the most prevalent chronic conditions. In addition, we excluded the studies with insufficient methodological details. 


\section{Conclusion}

This review showed a significant positive or negative association between personal and cultural beliefs and medication adherence. Illness perceptions and other beliefs may influence the actions of the individual and negatively or positively affect his or her health and taking medication.

This review draws attention to enhancing medication adherence amongst chronically ill patients, by changing their beliefs, illness perceptions and managing their negative emotional responses, and also gives an insight to the need for additional studies related to the impact of personal beliefs, acculturation and religion, on medication adherence to clarify the unexpected direction of association on medication adherence. In addition, this review highlights the gap in literature regarding studies which investigated the impact of different beliefs on medication adherence for patients diagnosed with COPD and/or asthma.

Health care providers need to understand the impact of illness perceptions, cultural and other beliefs on patients' adherence levels so that they can implement appropriate strategies to enhance adherence.

\section{Disclosure}

The authors report no conflicts of interest in this work.

\section{References}

1. World Health Organization. Hypertension; 2018; Available from: https://www.who.int/gho/ncd/risk_factors/blood_pressure_prevalence text/en/. Accessed September 25, 2018.

2. World Health Organization. Diabetes; 2018; Available from: http://www. who.int/news-room/fact-sheets/detail/diabetes. Accessed September 25, 2018.

3. Hsiao C-Y, Chang C, Chen C-D. An investigation on illness perception and adherence among hypertensive patients. Kaohsiung J Med Sci. 2012;28(8):442-447. doi:10.1016/j.kjms.2012.02.015

4. Mann DM, Ponieman D, Leventhal H, Halm EA. Predictors of adherence to diabetes medications: the role of disease and medication beliefs. J Behav Med. 2009;32(3):278-284. doi:10.1007/s10865-009-9202-y

5. Krauskopf K, Federman AD, Kale MS, et al. Chronic obstructive pulmonary disease illness and medication beliefs are associated with medication adherence. COPD. 2015;12(2):154-161. doi:10.3109/ 15412555.2014.922067

6. Feehan M, Ranker L, Durante R, et al. Adherence to controller asthma medications: 6-month prevalence across a US community pharmacy chain. J Clin Pharm Ther. 2015;40(5):590-593. doi:10.1111/ jcpt. 12316

7. Kretchy I, Owusu-Daaku F, Danquah S. Spiritual and religious beliefs: do they matter in the medication adherence behaviour of hypertensive patients? Biopsychosoc Med. 2013;7:7. doi:10.1186/1751-0759-7-15

8. Kardas P, Lewek P, Matyjaszczyk M. Determinants of patient adherence: a review of systematic reviews. Front Pharmacol. 2013;4(91). Available from: https://www.ncbi.nlm.nih.gov/pmc/articles/pmid/ 23898295/pdf/?tool=EBI. Accessed 2013.
9. Chia L, Schlenk E, Dunbar-Jacob J. Effect of personal and cultural beliefs on medication adherence in the elderly. Drugs Aging. 2006;23 (3):191-202. doi:10.2165/00002512-200623030-00002

10. Leventhal H, Diefenbach M, Leventhal E. Illness cognition: using common sense to understand treatment adherence and affect cognition interactions. Cognit Ther Res. 1992;16(2):143-163.

11. Jacobs A, Kemppainen JK, Taylor JS, Hadsell C. Beliefs about diabetes and medication adherence among lumbee indians living in rural Southeastern North Carolina. J Transcult Nurs. 2014;25 (2):167-175. doi:10.1177/1043659613515718

12. Aujla N, Walker M, Sprigg N, Abrams K, Massey A, Vedhara K. Can illness beliefs, from the common-sense model, prospectively predict adherence to self-management behaviours? A systematic review and meta-analysis. Psychol Health. 2016;31(8):931-958. doi:10.1080/ 08870446.2016.1153640

13. Abel MW, Greer BD. Spiritual/religious beliefs \& medication adherence in black women with hypertension. J Christ Nurs. 2017;34 (3):164-169. doi:10.1097/CNJ.0000000000000333

14. Hatah E, Lim KP, Ali AM, Mohamed Shah N, Islahudin F. The influence of cultural and religious orientations on social support and its potential impact on medication adherence. Patient Prefer Adherence. 2015;9:589. doi:10.2147/PPA.S82441

15. Berry JW. Acculturation and adaptation in a new society. Int Migrat. 1992;30:69-85. doi:10.1111/j.1468-2435.1992.tb00776.x

16. Huang Y-M, Shiyanbola OO, Smith PD. Association of health literacy and medication self-efficacy with medication adherence and diabetes control. Patient Prefer Adherence. 2018;12:793-802. doi:10.2147/PPA.S153312

17. Leung A, Health Literacy CP. Self-efficacy, and associated factors among patients with diabetes. Health Lit Res Pract. 2018;2(2):67-77. doi:10.3928/24748307-20180313-01

18. Soones TN, Lin JL, Wolf MS, et al. Pathways linking health literacy, health beliefs, and cognition to medication adherence in older adults with asthma. J Allergy Clin Immunol Pract. 2017;139(3):804-809. doi:10.1016/j.jaci.2016.05.043

19. Palacio A, Garay D, Langer B, Taylor J, Wood B, Tamariz L. Motivational interviewing improves medication adherence: a systematic review and meta-analysis. J Gen Intern Med. 2016;31 (8):929-940. doi:10.1007/s11606-016-3685-3

20. Conn V, Ruppar T, Chase J-A. Blood pressure outcomes of medication adherence interventions: systematic review and meta-analysis. J Behav Med. 2016;39(6):1065-1075. doi:10.1007/s10865-016-9730-1

21. Linn A, Vervloet M, van Dijk L, Smit E, van Weert J. Effects of tailored Internet interventions on medication adherence: a systematic review of the literature. Psychol Health. 2011;26:79.

22. Moher D, Liberati A, Tetzlaff J, Altman DG, Group P. Preferred reporting items for systematic reviews and meta-analyses: the PRISMA Statement. Open Med. 2009;3(3):3:e123-e130.

23. The Joanna Briggs Institute. Joanna Briggs Institute Critical appraisal tools for use in JBI Systematic Reviews: checklist for quasi-experimental studies (non-randomized experimental studies); 2017. Available from: http://joannabriggs.org/research/critical-appraisal-tools.html. Accessed April 23, 2019.

24. Smalls BL, Walker RJ, Hernandez-Tejada MA, Campbell JA, Davis KS, Egede LE. Associations between coping, diabetes knowledge, medication adherence and self-care behaviors in adults with type 2 diabetes. Gen Hosp Psychiatry. 2012;34(4):385-389. doi:10.1016/j.genhosppsych.2012.03.018

25. Rajpura J, Nayak R. Medication adherence in a sample of elderly suffering from hypertension: evaluating the influence of illness perceptions, treatment beliefs, and illness burden. J Manag Care Pharm. 2014;20(1):58-65. doi:10.18553/jmcp.2014.20.1.58

26. Shiyanbola OO, Unni E, Huang Y-M LC. The association of health literacy with illness perceptions, medication beliefs, and medication adherence among individuals with type 2 diabetes. Res Social Adm Pharm. 2017;14(9):824-830. doi:10.1016/j.sapharm.2017.12.005 
27. Li -W-W, Stewart AL, Stotts N, Froelicher ES. Cultural factors associated with antihypertensive medication adherence in Chinese immigrants. J Cardiovasc Nurs. 2006;21(5):354-362.

28. Tailakh AK, Evangelista LS, Morisky DE, Mentes JC, Pike NA, Phillips LR. Acculturation, medication adherence, lifestyle behaviors, and blood pressure control among Arab Americans. J Transcult Nurs. 2016;27(1):57-64. doi:10.1177/1043659614526456

29. Chen S, Tsai J, Lee W-L. The impact of illness perception on adherence to therapeutic regimens of patients with hypertension in Taiwan. J Clin Nurs. 2009;18(15):2234-2244. doi:10.1111/j.13652702.2008.02706.x

30. Chen S, Tsai J, Chou K. Illness perceptions and adherence to therapeutic regimens among patients with hypertension: a structural modeling approach. Int J Nurs Stud. 2011;48(2):235-245. doi:10.1016/j. ijnurstu.2010.07.005

31. Ashur ST, Shah SA, Bosseri S, Morisky DE, Shamsuddin K. Illness perceptions of Libyans with $\mathrm{t} 2 \mathrm{dm}$ and their influence on medication adherence: a study in a diabetes center in Tripoli. Libyan $\mathrm{J}$ Med. $2015 ; 10$.

32. Saarti S, Hajj A, Karam L, et al. Association between adherence, treatment satisfaction and illness perception in hypertensive patients. J Hum Hypertens. 2016;30(5):341-345. doi:10.1038/jhh.2015.86

33. Albargawi M, Snethen J, Al Gannass A, et al. Relationship between person's health beliefs and diabetes self-care management regimen. J Vasc Nurs. 2017;35(4):187-192. doi:10.1016/j.jvn.2017.07.002

34. Aflakseir A. Role of illness and medication perceptions on adherence to medication in a group of Iranian patients with type 2 diabetes. J Diabetes. 2012;4(3):243-247. doi:10.1111/j.1753-0407.2012.00183.x

35. Ku GMV, Kegels G. Knowledge, attitudes and perceptions of people with type 2 diabetes as related to self-management practices: results of a cross-sectional study conducted in Luzon, Philippines. Chronic Illn. 2015;11(2):93-107. doi:10.1177/1742395314538291

36. Nazir SU, Hassali MA, Saleem F, Bashir S, Aljadhey H. Association between diabetes-related knowledge and medication adherence: results from cross-sectional analysis. Altern Ther Health Med. 2016;22(6):8-13.

37. Chiu KC, Boonsawat W, Cho SH, et al. Patients' beliefs and behaviors related to treatment adherence in patients with asthma requiring maintenance treatment in Asia. J Asthma. 2014;51(6):652-659. doi:10.3109/02770903.2014.898772

38. Jankowska-Polańska B, Uchmanowicz I, Dudek K, Mazur G. Relationship between patients' knowledge and medication adherence among patients with hypertension. Patient Prefer Adherence. 2016;10:2437-2447. doi:10.2147/PPA.S117269

39. Wannasirikul P, Termsirikulchai L, Sujirarat D, Benjakul S, Health Literacy TC. Medication adherence, and blood pressure level among hypertensive older adults treated at primary health care centers. Southeast Asian J Trop Med Public Health. 2016;47(1):109-120.

40. Eh K, McGill M, Wong J, Krass I. Cultural issues and other factors that affect self-management of type 2 diabetes mellitus (T2D) by Chinese immigrants in Australia. Diabetes Res Clin Pract. 2016;119:97-105. doi:10.1016/j.diabres.2016.07.006

41. Arat S, Cock DD, Moons P, Vandenberghe J, Westhovens R. Modifiable correlates of illness perceptions in adults with chronic somatic conditions: a systematic review. Res Nurs Health. 2018;41 (2):173-184. doi:10.1002/nur.21852

42. Matsudaira T. Measures of psychological acculturation: a review. Transcult Psychiatry. 2006;43(3):462-487. doi:10.1177/13634615 06066989

43. Schoenthaler A, Montague E, Baier Manwell L, Brown R, Schwartz MD, Linzer M. Patient-physician racial/ethnic concordance and blood pressure control: the role of trust and medication adherence. Ethn Health. 2014;19 (5):565-578. doi:10.1080/13557858.2013.857764

44. Montague E, Asan O. Physician interactions with electronic health records in primary care. Health Syst. 2012;1(2):96-103. doi:10.1057/ hs. 2012.11
45. Schwartz SJ, Unger JB, Zamboanga BL, Szapocznik J. Rethinking the concept of acculturation: implications for theory and research. $\mathrm{Am}$ Psychol. 2010;65(4):237-251. doi:10.1037/a0019330

46. Broadbent E, Petrie KJ, Main J, Weinman J. The brief illness perception questionnaire. J Psychosom Res. 2006;60(6):631-637. doi:10.1016/j. jpsychores.2005.10.020

47. Horne R, Weinman J, Hankins M. The beliefs about medicines questionnaire: the development and evaluation of a new method for assessing the cognitive representation of medication. Psychol Health. 1999;14(1):1-24. doi:10.1080/08870449908407311

48. Cohen JL, Mann DM, Wisnivesky JP, et al. Assessing the validity of self-reported medication adherence among inner-city asthmatic adults: the medication adherence report scale for asthma. Ann Allergy Asthma Immunol. 2009;103(4):325-331. doi:10.1016/S1081-1206(10)60532-7

49. Hu WY, Tseng CD, Dai YT, Chao YM. An Exploration of the Drug Compliant Behaviors and Associated Factors of Hypertensive Patients. Chin J Public Health (Taipei). 1996;15:319e32.

50. Zyoud SH, Al-Jabi SW, Sweileh WM, Morisky DE. Relationship of treatment satisfaction to medication adherence: findings from a cross-sectional survey among hypertensive patients in Palestine. Health Qual Life Outcomes. 2013;11:191. doi:10.1186/1477-7525-11-83

51. Morisky DE, Ang A, Krousel-Wood M, Ward HJ. Predictive validity of a medication adherence measure in an outpatient setting. J Clin Hyperten. 2008;10(5):348-354.

52. Halm EA, Mora P, Leventhal H. No symptoms, no asthma: the acute episodic disease belief is associated with poor self-management among inner-city adults with persistent asthma. Chest. 2006;129 (3):573-580. doi:10.1378/chest.129.3.573

53. Haun JN, Valerio MA, McCormack LA, Sørensen K, Paasche-Orlow MK. Health literacy measurement: an inventory and descriptive summary of 51 instruments. J Health Commun. 2014;19(sup2):302-333. doi:10.1080/10810730.2014.936571

54. Fitzgerald JT, Davis WK, Connell CM, Hess GE, Funnell MM, Hiss RG. Development and validation of the diabetes care profile. Eval Health Prof. 1996;19(2):208-230. doi:10.1177/016327879601900205

55. Fitzgerald JT, Funnell MM, Hess GE, et al. The reliability and validity of a brief diabetes knowledge test. Diabetes Care. 1998;21 (5):706-710. doi:10.2337/diacare.21.5.706

56. Garcia AA, Villagomez ET, Brown SA, Kouzekanani K, Hanis CL. The Starr County Diabetes Education Study: development of the Spanish-language diabetes knowledge questionnaire. Diabetes Care. 2001;24(1):16-21. doi:10.2337/diacare.24.1.16

57. Saleem F, Hassali MA, Shafie AA, et al. PRM29 Translation and Validation Study of Morisky Medication Adherence Scale (MMAS): The Urdu Version for facilitating person-centered healthcare in Pakistan. International Journal of Person Centered Medicine. 2012;2(3). Available from: http://www.ijpcm.org/index.php/IJPCM/ article/view/251. Accessed April 23, 2019.

58. Saleem F, Hassali MA, Shafie AA, et al. PDB55 Translation and Validation Study of 14-Item Michigan Diabetes Knowledge Test (MDKT): The Urdu Version. Value in Health. 2011;14(7):A481.

59. Nathan RA, Sorkness CA, Kosinski M, et al. Development of the asthma control test: a survey for assessing asthma control. J Allergy Clin Immunol Pract. 2004;113(1):59-65. doi:10.1016/j.jaci.2003.09.008

60. Juniper EF, Buist AS, Cox FM, Ferrie PJ, King DR. Validation of a standardized version of the asthma quality of life questionnaire. Chest. 1999;115(5):1265-1270. doi:10.1378/chest.115.5.1265

61. Alzubaidi H, Mc Narmara K, Kilmartin GM, Kilmartin JF, Marriott J. The relationships between illness and treatment perceptions with adherence to diabetes self-care: a comparison between Arabic-speaking migrants and Caucasian English-speaking patients. Diabetes Res Clin Pract. 2015;110(2):208-217. doi:10.1016/j. diabres.2015.08.006

62. Albargawi M, Snethen J, Gannass AAL, Kelber S. Perception of persons with type 2 diabetes mellitus in Saudi Arabia. Int $J$ Nurs Sci. 2016;3(1):39-44. 
63. Marin G, Sabogal F, Marin BV, Otero-Sabogal R, Perez-Stable EJ. Development of a short acculturation scale for hispanics. Hisp J Behav Sci. 1987;9(2):183-205. doi:10.1177/07399863870092005

64. Chung VCH, Ma PHX, Lau CH, Wong SYS, Yeoh EK, Griffiths SM. Views on traditional Chinese medicine amongst Chinese population: a systematic review of qualitative and quantitative studies. Health Expect. 2014;17(5):622-636. doi:10.1111/j.1369-7625.2012.00794.x

65. Wang J, Bian R-W, Mo Y-Z. Validation of the Chinese version of the eight-item Morisky medication adherence scale in patients with type 2 diabetes mellitus. J Clin Gerontol Geriatrics. 2013;4(4):119-122. doi:10.1016/j.jcgg.2013.06.002

66. Jesse DE, Reed PG. Effects of spirituality and psychosocial well-being on health risk behaviors in Appalachian pregnant women. J Obstet Gynecol Neonatal Nurs. 2004;33(6):739-747. doi:10.1177/0884217504270669

67. Szaflarski M, Kudel I, Cotton S, Leonard AC, Tsevat J, Ritchey PN. Multidimensional assessment of spirituality/religion in patients with HIV: conceptual framework and empirical refinement. J Relig Health. 2012;51(4):1239-1260. doi:10.1007/s10943-010-9433-9

68. Hall MA, Camacho F, Dugan E, Balkrishnan R. Trust in the medical profession: conceptual and measurement issues. Health Serv Res. 2002;37(5):1419-1439.
69. Nunnally J, Bernstein I. Psychometric Theory. 3rd ed. New York: MacGraw-Hill; 1994.

70. Kim MT, Hill MN, Bone LR, Levine DM. Development and testing of the hill-bone compliance to high blood pressure therapy scale. Prog Cardiovasc Nurs. 2000;15(3):90-96.

71. Kripalani S, Risser J, Gatti ME, Jacobson TA. Development and evaluation of the Adherence to Refills and Medications Scale (ARMS) among low-literacy patients with chronic disease. Value Health. 2009;12(1):118-123. doi:10.1111/j.1524-4733.2008.00400.x

72. Erkoc SB, Isikli B, Metintas S, Kalyoncu C. Hypertension Knowledge-Level Scale (HK-LS): a study on development, validity and reliability. Int $J$ Environ Res Public Health. 2012;9 (3):1018-1029. doi:10.3390/ijerph9031018

73. Gim H, Kim B, Abreu JM. Asian American Multidimensional Acculturation Scale: Development, Factor Analysis, Reliability, and Validity. 2004. Available from: https://pdfs.semanticscholar.org/bffb/ dfb12a5bb81c48f079086ab5884be80f1dab.pdf. Accessed April 23, 2019.

74. Ishikawa H, Takeuchi T, Yano E. Measuring functional, communicative, and critical health literacy among diabetic patients. Diabetes Care. 2008;31(5):874-879. doi:10.2337/dc07-1932
Patient Preference and Adherence

\section{Publish your work in this journal}

Patient Preference and Adherence is an international, peer-reviewed, open access journal that focusing on the growing importance of patient preference and adherence throughout the therapeutic continuum. Patient satisfaction, acceptability, quality of life, compliance, persistence and their role in developing new therapeutic modalities and compounds to optimize clinical outcomes for existing disease

\section{Dovepress}

states are major areas of interest for the journal. This journal has been accepted for indexing on PubMed Central. The manuscript management system is completely online and includes a very quick and fair peer-review system, which is all easy to use. Visit http:// www.dovepress.com/testimonials.php to read real quotes from published authors. 